Ensino, Saúde e Ambiente -V5 (2), pp. 45-56, ago. 2012

\title{
CONHECIMENTO DOS ESTUDANTES DO ENSINO MÉDIO DE SANTANA DO IPANEMA SOBRE OS ESTERÓIDES ANABOLIZANTES ANDRÓGENOS
}

\section{SANTANA DO IPANEMA'S HIGHSCHOOL STUDENTS KNOWLEDGE ON ANABOLIC ANDROGENIC STEROIDS}

\author{
Jorge Paulo Gonzaga ${ }^{1}$, Sérgio Alves Martins ${ }^{1}$, Elian Sandra Alves de Araújo ${ }^{2}$, Solma \\ Lucia Souto Maior de Araújo Baltar ${ }^{3}$ \\ ${ }^{1}$ Discentes da Universidade Estadual de Alagoas/ Ciências Biológicas/ \\ paulinho_0208@hotmail.com/sergiomartins2008@hotmail.com \\ ${ }^{2}$ Mestranda PPGECIM/UFAL/ Professora da Universidade Estadual de Alagoas/ Ciências Biológicas/ \\ profelian.uneal@gmail.com \\ ${ }^{3}$ Doutoranda PPGIT/UFPE/ Professora da Universidade Estadual de Alagoas/ Ciências Biológicas/ \\ slbaltar@hotmail.com
}

\section{RESUMO}

Desde os primórdios das civilizações a busca pela força e beleza vem sendo evidenciada, fato que tem estimulado o desenvolvimento de métodos e substâncias promotoras de alterações anatômicas e fisiológicas no organismo humano. Dentre estas substâncias estão os esteróides anabolizantes andrógenos - EAA, naturalmente produzidos pelo organismo, mas que podem ter sua quantidade natural alterada pelo consumo de suas formas sintéticas. No entanto, quando utilizadas indevidamente, estas substâncias ocasionam danos ao indivíduo. O objetivo deste estudo foi investigar o conhecimento dos estudantes do Ensino Médio da rede pública de Santana do Ipanema AL, sobre EAA por meio da aplicação de questionários. Todos os participantes alegaram ter ouvido falar em anabolizantes, a maioria por meio da televisão, fato elucidado pela ausência de conhecimento dos reais efeitos do consumo dos EAA, bem como pela indicação da ausência de trabalhos educacionais voltados para a prevenção do contato dos adolescentes com estas substâncias.

Palavras-chave: Esteroides anabolizantes. Estudantes. Ensino Médio.

\begin{abstract}
Since the dawn of civilization the search for strength and beauty has been demonstrated, a fact that has stimulated the development of methods and substances that promote anatomical and physiological changes in the human body. Among these substances are anabolic androgenic steroids - AAS, naturally produced by the body, but that can have your natural amount altered by the consumption in your synthetic forms. However, when improperly used, these substances may cause damage to the individual. The aim of this paper was to investigate the knowledge of high school students of the public school of Santana of Ipanema - AL on AAS through the use of questionnaires. All participants claimed to have heard of anabolic steroids, mostly through television, fact elucidated by the absence of knowledge of the real effects of the consumption of AAS, as well as for the indication of the absence of educational works on prevention of the adolescents contact with these substances.
\end{abstract}

Key words: Anabolic steroids. Students. High School. 
Ensino, Saúde e Ambiente - V5 (2), pp. 45.56, ago. 2012

\section{INTRODUÇÃO}

O mundo moderno traz aos indivíduos a preocupação com a aparência corporal, e a busca pela perfeição tem sido retratada e apontada pelo consumismo e individualismo. O corpo tornou-se um objeto, e o que há pouco tempo atrás, parecia se manifestar apenas nas mulheres, hoje em dia, tornou-se popular entre os indivíduos do sexo masculino que almejam ficar mais fortes e musculosos (GIACOMINI, 2004; MARTINS et al., 2005).

Não é de hoje que pessoas comuns e atletas usam anabolizantes com o objetivo de melhorar sua performance (IRIART et al., 2009). Desde os primórdios da existência humana, a procura por uma força física maior é evidenciada. Há registros de que as primeiras civilizações costumavam comer órgãos de animais e pessoas, na fé de que assim aumentariam à força e o desempenho sexual, além de observarem que a castração em animais provocava sua infertilidade, diminuição de força e agressividade (SANTOS, 2007).

No organismo humano o aumento muscular, principalmente nos tecidos musculares e ósseos é promovido pelos esteroides anabolizantes um grupo de hormônios esteroides naturais - que são sintetizados - por combinações variadas de suas propriedades, dependendo do efeito que se deseja ter sobre o corpo (LIMA \& SANTOS, 2009).

Apesar de serem conhecidos a muito tempo, apenas no ano de 1958 foi que o primeiro esteróide anabolizante foi lançado no mercado com o nome de Dianabol, passando a ser vendido legalmente em 1965. Estes eram usados por atletas e médicos livremente, vindo a ser proibido em 1972 nos jogos Olímpicos de Munique (NETO, 2002).

Os esteróides anabolizantes foram proibidos não só para atletas pelo chamado “doping”, mas para todas as pessoas que quisesse adquirir a substância. Em $1^{\circ}$ de março de 1991 tornou-se um medicamento que só poderia ser adquirido por meio de prescrição médica (SILVA et al., 2002).

A pesar desta proibição o consumo dos esteróides não cessou. De acordo com o Centro Brasileiro de Informações sobre Drogas Psicotrópicas (2003) na maioria das vezes o comércio destas substâncias vem sendo realizado de forma ilícita, dificultando o trabalho das autoridades públicas em realizar as devidas fiscalizações. Pesquisas indicam que no ano de 1994, mais de um milhão de jovens já haviam usado 
anabolizantes nos Estados Unidos, enquanto que no Brasil a abrangência pelo tema é recente. Porém, sabe-se que os consumidores preferenciais são do sexo masculino que estão na faixa etária que varia entre 18 e 34 anos de idade (IRIART et al., 2009).

Apesar de estes dados indicarem o maior consumo entre os indivíduos adultos, o trabalho realizado por Aquino (2001) indica um crescente aumento do consumo dos esteróides anabolizantes entre os adolescentes praticantes de musculação, que por sua vez estão em busca de resultados imediatos e querem aumentar os músculos a qualquer custo. Já o trabalho de Osório (2011) aponta para um aumento de 39\% no consumo de esteróides entre estudantes do nível fundamental, desde o ano de 1996.

A adolescência é considerada a fase das descobertas, de formação de novas opiniões e novos conceitos que mudam a todo instante. É a idade em que há necessidade de auto-afirmação, o que prevalece é a insegurança, o novo é muito chamativo e convida o adolescente para novas experiências, e as influências partem muito do meio onde vivem (AQUINO, 1998).

Em busca da aceitação pela sociedade, muitos adolescentes procuram os esteróides anabolizantes, por julgarem ser este o meio mais rápido para alcançar o objetivo de ter um corpo perfeito. As possibilidades destes resultados seduzem os jovens e adolescentes, compensando um sentimento de baixa auto-estima, a vontade de crescer rapidamente e aumentar os músculos entusiasma estes indivíduos, e por falta de conhecimento e informação, fazem uso destas substâncias sem nenhuma restrição (SANTOS, 2007).

Esteróides anabolizantes é um tema comum nas rodas de conversas entre os adolescentes. Destarte, a escola torna-se responsável por colocar em pauta este tema, de modo a preparar um espaço onde professores e alunos compartilhem conhecimento e possam por meio do trabalho de sensibilização desenvolver uma consciência crítica sobre os efeitos que os esteróides podem causar sobre o organismo humano (OSORIO, 2011).

A escola desempenha uma função social essencial à formação dos indivíduos, na forma em que os saberes escolhidos por uma sociedade e seus valores serão passados e construídos mediante ações educativas. Sendo assim, a escola não pode se limitar apenas a passar informações relacionadas a matérias, mas deve preocupar-se com a formação moral do indivíduo, atentando para os temas emergentes na comunidade na qual está inserida (BRASIL, 2006). 
Neste contexto, a escola assume um importante papel, por ter potencialidade para o desenvolvimento de um trabalho sistematizado e contínuo e deve fornecer elementos que capacitem os alunos para uma vida saudável, incorporando ações educativas que desenvolvam as aptidões e capacidades individuais do educando, visto ser a adolescência ser uma fase decisiva para a construção cidadã do indivíduo (BRASIL, 2006).

Nesse sentido, é preciso desenvolver discussões de modo amplo, interdisciplinar, que mobilize e envolva os alunos como a realização de pesquisas e divulgação das informações produzidas por meio de seminários ou debates, visto que são formas de aprender, de socializar conhecimentos e de desenvolver atitudes de compromisso com a saúde coletiva, não devendo ficar restrito a uma disciplina ou área de conhecimento, e envolver todo o corpo docente da escola (ALBERTINI, 1998).

Diante do exposto é premente aqui destacar a necessidade da realização de trabalhos escolares que visem à divulgação das informações sobre os aspectos legais do uso dos esteróides bem como, sobre os prejuízos causados pelo uso indevido destas substâncias, pois apesar da divulgação de tamanhos danos, pouco tem sido feito para se prevenir a disseminação do uso dos EAA entre os jovens e adolescentes. O presente estudo teve por objetivos investigar o conhecimento dos estudantes do primeiro ano do Ensino Médio de uma escola da cidade de Santana do Ipanema sobre esteróides anabolizantes andrógenos e sugerir ações para as instituições de ensino desta localidade.

\section{METODOLOGIA}

Esta pesquisa foi realizada na Escola Estadual Laura Chagas da Assis localizada no município de Santana do Ipanema, na região centro-oeste do Estado de Alagoas.

O método adotado para investigação foi o quali-quantitativo. A coleta dos dados foi realizada em uma turma do primeiro ano do Ensino Médio, através da aplicação de questionário semi-estruturado composto por oito questões referentes a informações gerais sobre esteróides anabolizantes andrógenos.

Posteriormente a coleta dos dados, a fim da promoção de conhecimento e informações inerentes ao tema abordado no questionário, foi ministrada uma palestra educativa para os estudantes participantes deste trabalho. 
Os dados obtidos foram tabulados e analisados no Software Microsoft Office Excel 2007 para Windows XP Professional, sendo expressos em tabelas e gráficos, deste modo, facilitando a impressão do fenômeno em estudo, e evidenciando alguns aspectos particulares de interesse dos pesquisadores (GUEDES, 2005).

\section{RESULTADOS E DISCUSSÃO}

Participaram desta pesquisa 22 alunos do primeiro ano do Ensino Médio, cuja média de idade apresentada foi de 16 anos, sendo que 40,91\% (9) eram do sexo masculino e 59,09\% (13) eram do sexo feminino.

No tocante ao nível de escolaridade dos pais dos participantes, percebe-se um maior percentual de pais com nível fundamental $(45,45 \%)$ e médio $(40,91 \%)$, seguidos de pais com curso superior $(6,82 \%)$ e em menor número $(2,27 \%)$ os pais são analfabetos (Figura 1).

É presumível que quanto maior o nível de escolaridade dos pais, mais estes possam contribuir com uma melhor formação para seus filhos, bem como influenciar positivamente no desempenho escolar destes, sendo que os filhos de pais analfabetos ou que não terminaram o ensino fundamental têm $480 \%$ de chance de apresentar um desempenho inferior quando comparados a filhos de pais com curso superior completo (ARRUDA et al., 2010).

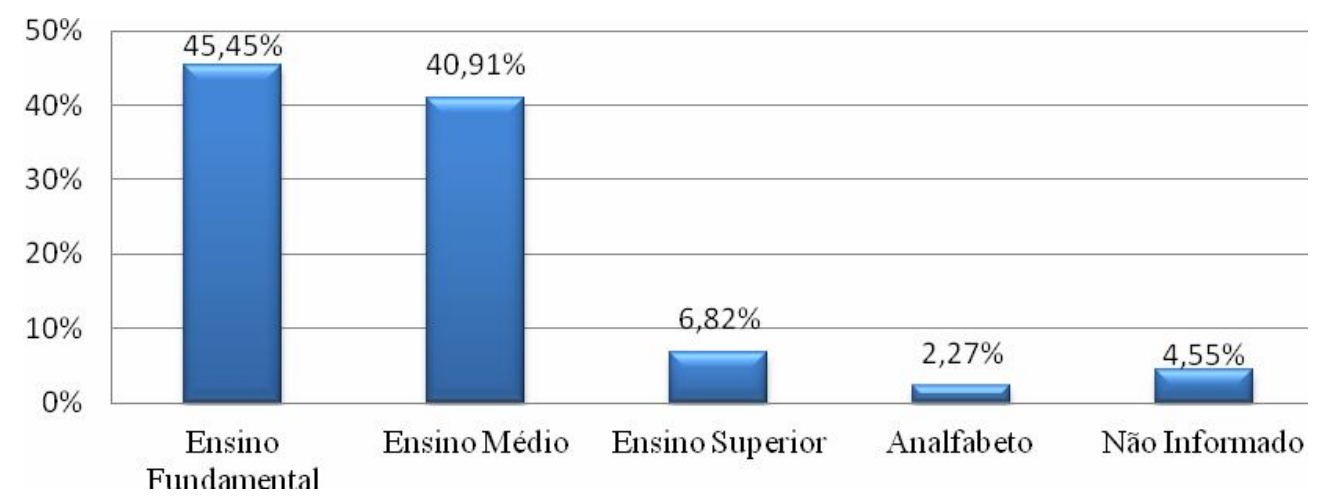

Figura 1 - Grau de instrução dos pais dos estudantes da turma do primeiro ano do ensino médio da Escola Estadual Laura Chagas de Assis de Santana do Ipanema (AL), 2011.

Mesmo que o nível de escolaridade prevalente nesta pesquisa tenha sido o nível fundamental e médio, este não pode ser considerado um fator de interferência sobre as informações que os estudantes possuem a respeito dos anabolizantes, visto que todos os 
participantes afirmaram já ter ouvido falar sobre estas substâncias. Contudo, ao citarem as fontes de suas informações, nenhum deles se referiu à família, como demonstrado na tabela 1. As fontes mais citadas foram televisão $(50,00 \%)$, seguida de escola $(36,36 \%)$ e $\operatorname{amigos}(18,18 \%)$.

Tabela 1 - Fontes de informação sobre esteróides anabolizantes andrógenos mais citadas por estudantes da turma do primeiro ano do ensino médio da Escola Estadual Laura Chagas de Assis de Santana do Ipanema (AL), 2011.

\begin{tabular}{lcc}
\hline \multicolumn{1}{c}{ Fonte } & Número de participantes & Percentual \\
\hline Televisão & 11 & $50,00 \%$ \\
Escola & 8 & $36,36 \%$ \\
Amigos & 4 & $18,18 \%$ \\
Academia & 3 & $13,64 \%$ \\
Internet & 3 & $13,64 \%$ \\
Rua & 2 & $9,09 \%$ \\
\hline
\end{tabular}

Diferentemente do trabalho de Costa et al. (2007), onde foi verificado que a maior parte da amostra estudada nunca tinha ouvido falar em esteróides anabolizantes, no presente estudo, todos os participantes afirmaram que já tiveram acesso ao assunto. Entretanto, não se sabe o grau de confiabilidade das informações obtidas por estes, visto que o ambiente escolar, que é capaz de promover o conhecimento científico, foi menos mencionado que a televisão que predominou em relação aos outros itens.

De acordo com $16(72,73 \%)$ alunos participantes a temática esteroide anabolizante andrógeno nunca foi abordado ou comentado em sala de aula pelos professores, enquanto $6(27,27 \%)$ entrevistados responderam que sim, ou seja, que o assunto já foi abordado em algum momento pelo professor (Figura 2).

Discutir sobre anabolizantes na escola é buscar um espaço onde os alunos, professores e a comunidade escolar tenham a oportunidade de se conscientizar e se preparar para os efeitos nocivos das drogas (TAVARES et al., 2003 apud COSTA et al., 2007). Por se constituir espaço de formação do indivíduo deve atentar para os assuntos emergentes em sua comunidade. $\mathrm{O}$ fato é abrir mão da estrutura conteudista tradicional e abrir espaço para o contexto social, econômico, político e ambiental que permeia seus alunos, transformando assim o ensino em algo prazeroso e significativo para o educando. Percebe-se, dessa forma, que há necessidade de maiores informações e intervenções educativas em ambientes escolares sobre os esteróides anabolizantes, em 
especial com os adolescentes, visto que estes estão mais vulneráveis a aceitabilidades de mudanças repentinas (LIMA \& SANTOS, 2009).

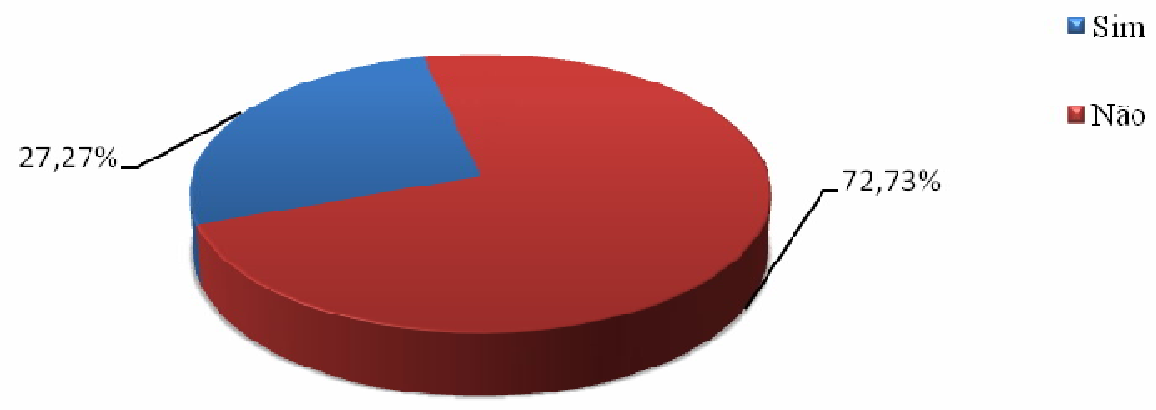

Figura 2 - Resposta dos estudantes da turma do primeiro ano do ensino médios da Escola Estadual Laura Chagas da Assis de Santana do Ipanema (AL), 2011, quanto à abordagem do assunto esteróides anabolizantes andrógenos em sala de aula pelos professores.

Apesar de todos os estudantes admitirem um prévio contato com informações inerentes aos esteróides anabolizantes, 7 (31,82\%) deles responderam não saber o que são tais substâncias, enquanto $15(68,18 \%)$ afirmaram saber do que se trata, como podemos observar na figura 3.

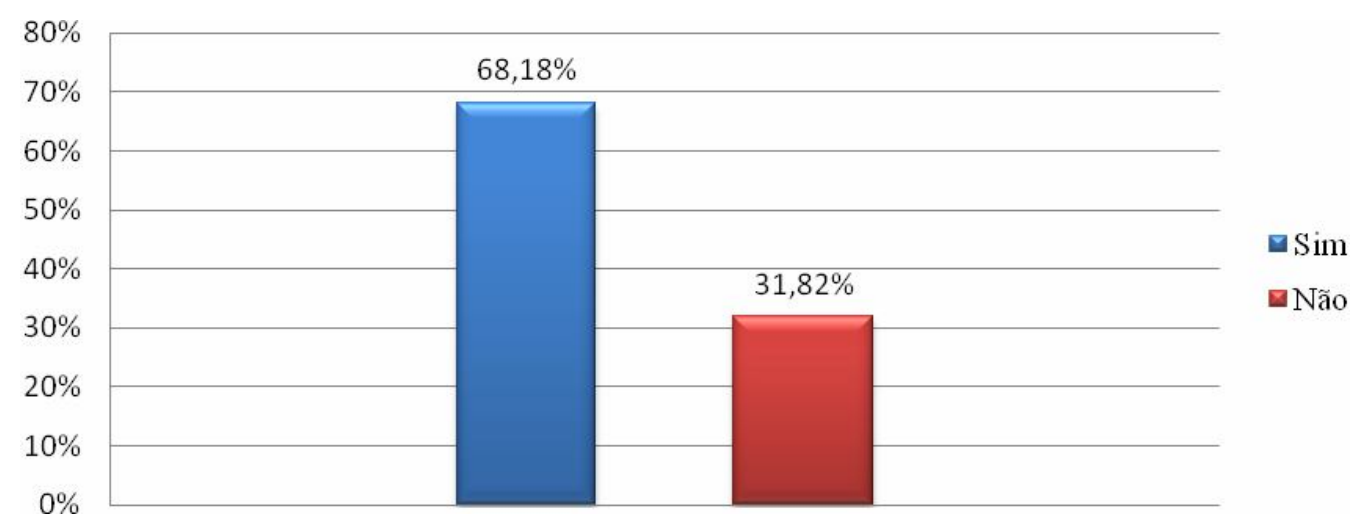

Figura 3 - Conhecimento dos estudantes da turma do primeiro ano do ensino médio da Escola Estadual Laura Chagas de Assis de Santana do Ipanema (AL), 2011, sobre o que são esteróides anabolizantes andrógenos.

Voluntariamente alguns estudantes ampliaram suas respostas considerando que os anabolizantes são substâncias que atuam no organismo promovendo o aumento da massa muscular. Essa resposta se aproxima do conceito de esteróides anabolizantes que de acordo com Lima e Santos (2009), são um grupo de hormônios esteróides naturais e sintéticos que causam o aumento muscular, principalmente nos tecidos musculares e 
ósseos, podendo ter combinações variadas de propriedades, dependendo do efeito que se deseja ter sobre o corpo.

Com relação à utilidade dos esteróides anabolizantes, 16 participantes $(72,73 \%)$ afirmaram conhecê-la. Estes destacaram o emprego dos esteróides anabolizantes para o ganho de massa muscular e dois dos participantes justificaram suas respostas declarando que os esteróides servem para uso veterinário, e 6 (27,27\%) dos participantes responderam que não sabiam a finalidade destas substâncias (figura 4).

Este resultado, a exemplo do anterior, revela a ligação direta que os estudantes fazem entre anabolizantes e o aumento da musculatura, resultado provavelmente de discussões divulgadas pela mídia.

Um número crescente de jovens acredita que o uso de esteróides anabolizantes androgênicos (EAA), causa um ganho repentino de massa muscular, tão grande que ultrapassa aquele alcançado por meio dos exercícios físicos (MARTINS et al., 2005). É reconhecido que os EAA podem aumentar a força muscular através de efeitos psicológicos, mas existe dúvida se os EAA melhoram a força muscular na ausência de exercícios concomitantes (LISE et al., 1999).

Vale lembrar que as indicações do uso de anabolizantes não se aplicam exclusivamente ao aumento da massa muscular. Segundo a FDA (Federal Drug Association) as indicações médicas aprovadas para o uso de EAA referem-se, entre outros, a diminuição da dor óssea na osteoporose, catabolismo induzido por corticosteróide, anemia grave, câncer de mama metastático ou deficiência hormonal masculina (LISE et al., 1999).

Aos participantes do estudo também foi perguntado sobre os prejuízos que o uso de esteróides anabolizantes pode causar à saúde, e 11 entrevistados (50,00\%) responderam conhecer os malefícios causados pelo uso de tais substâncias e os outros $11(50,00 \%)$ referiram não ter conhecimento (Figura 4), sendo que os problemas mais citados foram: problemas cardíacos $(18,18 \%)$, câncer $(9,09 \%)$ e morte $(9,09 \%)$.

De acordo com IRIART et al,. (2009), entre os inúmeros efeitos colaterais indesejados, os usuários que fazem uso de anabolizantes podem ter calvície, acne, se tornam agressivos, impotência sexual, insônia, cefaléias, aumento do mau colesterol e diminuição do bom colesterol, ginecomastia, complicações cardíacas e atrofia testicular. Nas mulheres pode aparecer pelo engrossamento da voz, hipertrofia do clitóris e problemas com a menstruação. 


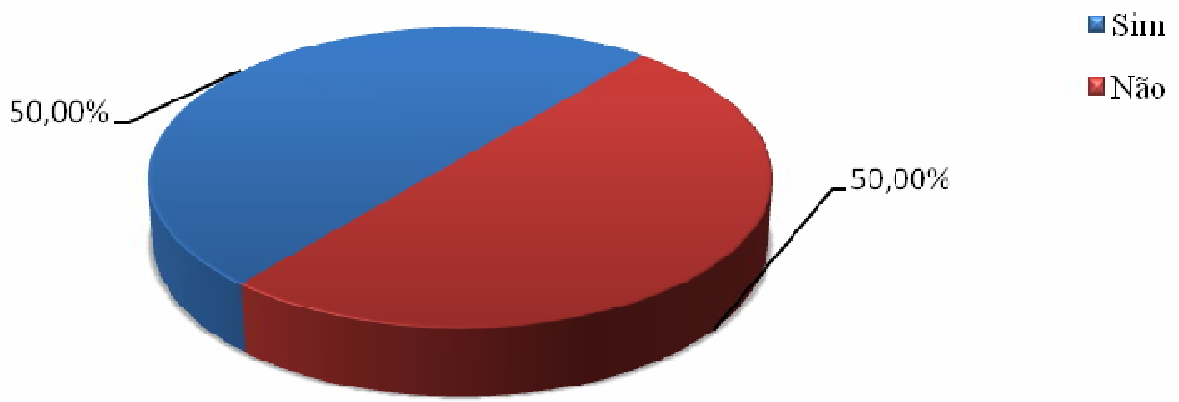

Figura 4 - Conhecimento dos estudantes da turma do primeiro ano do ensino médio da Escola Estadual Laura Chagas de Assis de Santana do Ipanema (AL), 2011, sobre os prejuízos do uso de esteróides anabolizantes andrógenos.

Em se tratando das diferentes formas de uso dos esteróides anabolizantes, 12 dos participantes $(54,55 \%)$ informaram saber como estes são usados enquanto que 10 $(45,45 \%)$ responderam que não conheciam (Figura 5).



Figura 5 - Conhecimento dos estudantes da turma do primeiro ano do ensino médio da Escola Estadual Laura Chagas de Assis de Santana do Ipanema (AL), 2011, sobre as formas de uso dos esteróides anabolizantes andrógenos.

Ao explicar suas respostas, todos os indivíduos que declararam conhecer as formas de uso dos EAA, comprovaram possuir entendimento de como os anabolizantes são usados, pois os mesmos relataram que os esteróides podem ser usados de forma oral por meio de comprimidos, na forma injetável ou pelas duas formas. 
Estas explicações equiparam-se com as do Centro Brasileiro de Informações sobre Drogas Psicotrópicas (2003), quando evidencia que os esteróides anabolizantes tanto podem ser tomados na forma de comprimidos quanto em injeções e no caso de uso ilícito pode levar o usuário a utilizar doses centenas de vezes maiores do que a recomendação médica.

\section{CONCLUSÃO}

O uso dos esteróides anabolizante constitui-se um grave problema de saúde pública por dois motivos: o consumo indevido e pela forma ilícita como vem sendo comercializado.

É evidente que a ausência de conhecimento de jovens e adolescentes sobre estas sustâncias facilita o contato com as mesmas, visto que estes acreditam no milagre do aumento da massa muscular, o que foi evidenciado com esta pesquisa e corroborado por outros trabalhos aqui apresentados.

De igual modo percebe-se a necessidade da realização de trabalhos acadêmicos sobre esta temática já que podemos afirmar que estes são pouco produzidos, o que dificultou o acesso a literatura para sua realização.

A ausência de um programa educacional que vise realmente à prevenção do consumo de anabolizantes e outras drogas no mais amplo sentido da palavra também se faz notória, visto que ficou evidente a inexistência de trabalhos transversais na escola. Destarte, a ausência de conhecimento científico sobre esta temática merece ser considerada e trabalhada pela comunidade escolar, que deve superar seus medos e preconceitos podendo assim falar de modo claro e real com os educandos.

Para o desenvolvimento de tais projetos é necessário que haja a mobilização de todo o corpo docente e não docente das escolas, bem como das famílias que devem estar em constante e sintonia com a comunidade escolar, na busca pelo desenvolvimento do melhor trabalho na formação cidadã do educando.

A participação direta de órgãos públicos como a Secretaria de Saúde e de Segurança Pública é também de extrema importância. Para que isso ocorra, é imprescindível que haja um real interesse dos governos no âmbito Federal, Estadual e Municipal, de forma a proporcionar investimento em recursos financeiros, materiais e humanos adequados, por tempo prolongado visando à erradicação do problema. 
Ensino, Saúde e Ambiente -V5 (2), pp. 45-56, ago. 2012

Sendo assim, podemos afirmar que se faz necessário à criação de um programa de prevenção ao consumo de Esteróides Anabolizantes nas redes de ensino do município de Santana do Ipanema (AL), de modo a promover uma educação que possibilite aos estudantes a apropriação de conhecimentos com base nos quais possam agir conscientemente diante desta temática.

\section{REFERÊNCIAS}

ALBERTINI, Paulo. Drogas: mal estar e prazer. In: Aquino Julio Groppa (Org). Drogas na escola: Alternativa Teóricas e Práticas 3. ed. São Paulo: Summus, 1998. 45-57p.

AQUINO NETO, Francisco Radler de. O papel do atleta na Sociedade e o controle de dopagem no esporte. Revista Brasileira de Medicina do Esporte, v. 7, n. 4, p. 138148, jul./ago. 2001. Disponível em:

<http://www.scielo.br/pdf/rbme/v7n4/v7n4a05.pdf>. Acesso em: 18 nov. 2011.

AQUINO, Julio Groppa (org.). A Escola e as novas demandas sociais: as drogas como tema transversal. In:__. Drogas na escola: alternativas teóricas e práticas. 3. ed. São Paulo: Summus, 1998. 83-103p.

ARRUDA, Marco Antônio; ALMEIDA, Mauro; GALLI, Federica; POLANCZYK, Guilherme; BIGAL, Marcelo; GUIDETTI, Vincenzo; ALBUQUERQUE, Regina.

Projeto Atenção Brasil: saúde mental e desempenho escolar em crianças e adolescentes brasileiros. Análise dos resultados e recomendações para o educador com base em evidências científicas. Ribeirão Preto, SP, Brasil: Instituto Glia; 2010.

Disponível em: <http://www.aprendercrianca.com.br/aprender-crianca-2010-dp249>. Acesso em: 04 fev. 2012.

BRASIL. Ministério da Educação. Coordenação de educação Infantil - DPEIEF/SEB. Revista Criança - do professor de educação infantil. Brasília, n. 42, dez. 2006.

CENTRO BRASILEIRO DE INFORMAÇÕES SOBRE DROGAS PSICOTRÓPICAS. Esteróides anabolizantes. São Paulo, 2003. Disponível em:

<http://www.cebrid.epm.br/folhetos/anabolizantes_.htm>. Acesso em: 05 dez. 2011.

COSTA, Diene Pires; SILVA, Letícia Soares; ALVIM, Marley Pereira B. Esteróides Anabolizantes: uma visão dos alunos que cursam a $8^{\mathrm{a}}$ série. Movimentum: revista digital de educação física, v. 2, n. 2, p. 1-14, ago./dez. 2007. Disponível em: <http://www.unilestemg.br/movimentum/Artigos_V2N2_em_pdf/movimentum_V2_N2 _diene_costa_leticia_silva_2_2006.pdf>. Acesso em 01 dez. 2011.

GIACOMINI, Sonia Maria. O Corpo como cultura e a cultura do corpo: uma explosão de significados. Physis: revista saúde coletiva, v. 14, n. 2, p. 395-423, 2004.

Disponível em: <http:// http://www.scielo.br/pdf/physis/v14n2/v14n2a14.pdf>. Acesso em: 10 ago. 2011. 
GUEDES, Terezinha Aparecida; ACORSI, Clédnina Regina Lonardan; MARTINS, Ana Beatriz Tozzo; JANEIRO, Vanderly. Estatística descritiva. Projeto de Ensino: aprender fazendo estatística, 2005. Disponível em:

<http://www.tecnicodepetroleo.ufpr.br/apostilas/matematica/estatisticadescritiva.pdf $>$. Acesso em: 03 fev. 2012.

IRIART, Jorge Alberto Bernstein; CHAVES, José Carlos; ORLEANS, Roberto Ghignone de. Culto ao corpo e uso de anabolizantes entre praticantes de musculação. Cadernos de Saúde Pública, Rio de Janeiro, v. 25, n. 4, p. 773-782, abr. 2009. Disponível em:

<http://www.scielosp.org/scielo.php?pid=S0102311X2009000400008\&script=sci_artte xt>. Acesso em: 19 fev. 2011.

LIMA Ozenilda Dulce Marinho de; SANTOS Azenildo Moura. Importância da informação sobre o abuso do uso de esteróides anabolizantes andrógenos na adolescência. Revista Digital, ano 14, n. 134, jul. 2009. Disponível em: <www.efdeportes.com/edf134/esterpoides-anabolizantes-androgenos>. Acesso em: 29 jan. 2011.

LISE, Michelle Larissa Zini; SILVA, Tatiana Sudbrack da Gama e; FERIGOLO, Maristela; BARROS, HelenaMariaTannhauser. O abuso de esteróides anabólicoandrogênicos em atletismo. Revista da Associação Médica Brasileira, v. 45, n. 4, p. 364-70, set./dez.1999. Disponível em:

<http://www.scielo.br/scielo.php?script=sci_arttext\&pid=S0104-42301999000400014>. Acesso em: 16 nov. 2011.

MARTINS, Cristiane Mega; CARIJÓ, Felipe H; ALMEIDA, Maria Clara de; SILVEIRA, Maurício da; MIRAILH, Michelly Xavier Nunes; PEIXOTO, Mônica Monteiro; MARTINS, Richarlls; RAMALHO, Thaís Mendes; FRANCO, Alfred Sholl. Efeitos Psicológicos do abuso de anabolizantes. Ciências \& Cognição, v. 05, p. 84-91, jul. 2005. Disponível em: <http://www.cienciasecognicao.org>. Acesso em: 29 mai. 2011.

NETO, Waldemar Marques Guimarães. Além do Anabolismo. 2. ed. São Paulo: Phorte, 2002.

OSORIO, Luis Felipe Baumotte. Os Esteróides Anabolizantes e a Sociedade. Brasília, 2011.

SANTOS, Azenildo Moura. O mundo anabólico: Análise do uso de Esteróides Anabólicos nos Esportes. 2. ed. São Paulo: Manole, 2007. Disponível em: <http://migre.me/5HhUx>. Acesso em: 15 ago. 2011.

SILVA, Paulo Rodrigo Pedroso da; DANIELSKI, Ricardo; CZEPIELEWSKI, Mauro Ântonio. Esteróides anabolizantes no esporte. Revista Brasileira de Medicina do Esporte, v. 8, n. 6, p. 235-243, nov./dez. 2002. Disponível em: <http://www.scielo.br/pdf/rbme/v8n6/v8n6a05.pdf>. Acesso em: 19 fev. 2011. 